RIACH, I.C.F. (1966) The Stella Index-A relationship between the area of the sella turcica and the lateral area of the skull. Brit. J. Radiol. 39, 824.

Smith, D.W., Blizzard, R.M. \& Wilkins, L. (1957) The mental prognosis in hypothyroidism of infancy and childhood. Pediatrics, 19, 1011.

Von Harnack, G.A. (1953) Eineiige Zwillinge mit diskordanter Hypothyreose. Arch. Kinderheilk, 146, 60.
Von Harnack, G.A., Horst, W., Lenz, W. \& ZukschWERDT, L. (1958) Homotransplantation of thyroid tissue in uniovular twins. Germ. med. Mth. 3, 172.

WarkanY, J. \& SelkiRK, J. (1955) Discordant monozygotic twins. Amer. J. Dis. Child. 89, 144.

WILKINs, L. (1965) The Diagnosis and Treatment of Endocrine Disorders in Childhood and Adolescence, 3rd edn. Thomas, Springfield, Illinois.

\title{
IATS activity, exophthalmos and digital clubbing associated with myxoedema
}

\author{
Peter Beighton \\ M.R.C.P., M.R.C.P.(Ed.), D.T.M. \& H. \\ Formerly Medical Registrar, Hillingdon Hospital; \\ Now Medical Registrar, St Thomas' Hospital
}

THE ASSOCIATION of exophthalmos and finger clubbing with thyrotoxicosis is well known (Malkinson, 1963). It has been postulated that the long acting thyroid stimulator (LATS) might be the common aetiological factor.

The case described is that of a patient with proven myxoedema, who had never had any previous episodes of hyperthyroidism, who exhibited exophthalmos and digital clubbing, and in whom the serum LATS level was raised. In addition she had rheumatoid arthritis and pernicious anaemia. The significance of these associations is discussed.

\section{Case report}

The patient, a 67-year-old spinster, was admitted to Hillingdon Hospital in June 1966. In 1944 she had experienced gradual 'slowing down' together with changes in her skin and hair. Myxoedema was diagnosed clinically and treatment with thyroxine had continued from that time until 4 months before when she had neglected to take her tablets. In 1964 proptosis developed and has progressed. Tarsorrhaphy was performed in 1965 for a left-sided corneal ulcer. She developed joint symptoms in 1960 which led to a a diagnosis of rheumatoid arthritis. At this time she had an ESR of $50 \mathrm{~mm} / \mathrm{hr}$ and a negative test for the rheumatoid factor. By 1966 she was unable to walk and surgical arthrodesis of the left knee joint was later carried out.

Pernicious anaemia was diagnosed in 1966 during routine investigation of a symptomless anaemia. In 1930 she had rheumatic fever but there were no apparent sequelae. She had never had a goitre.
There was no family history of thyroid disorder, arthritis or pernicious anaemia.

Examination. The patient was a middle-aged lady with sparse, coarse hair, a dry thickened skin and the facial appearance characteristic of myxoedema (Fig. 1). Her height was $5 \mathrm{ft} 2$ in. (152.5

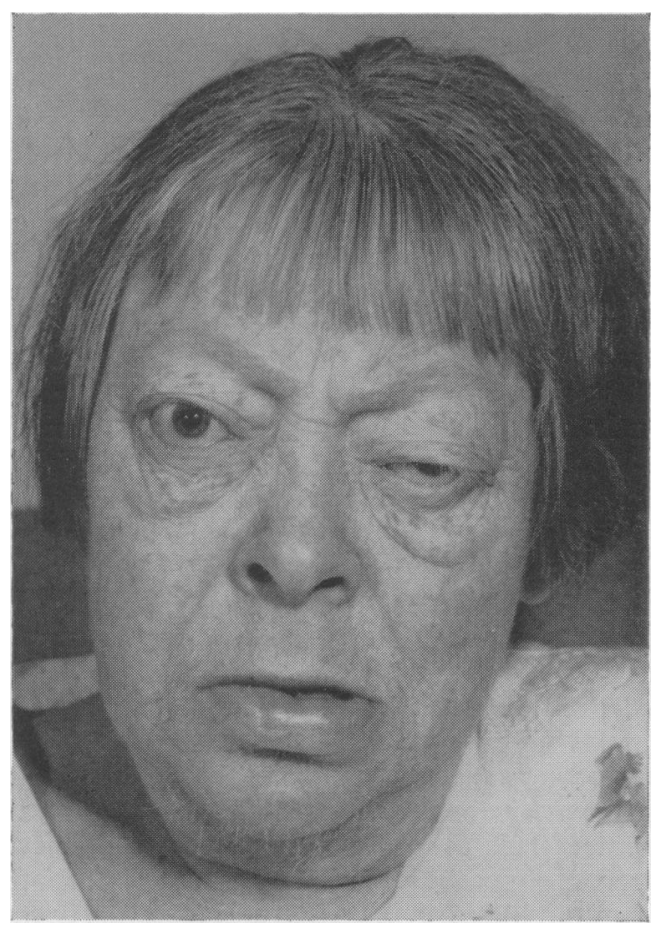

Fig. 1. 
$\mathrm{cm})$ and weight $10 \mathrm{st} 3 \mathrm{lb}(141.5 \mathrm{~kg})$. She was slow in thought and action, her voice was gruff and her tendon reflexes exhibited delayed relaxation. The thyroid gland was impalpable.

Marked finger clubbing was present (Fig. 2) and pretibial myxoedema affected the shins and both feet (Fig. 3). In these areas the skin was raised in irregular firm dimpled swellings.

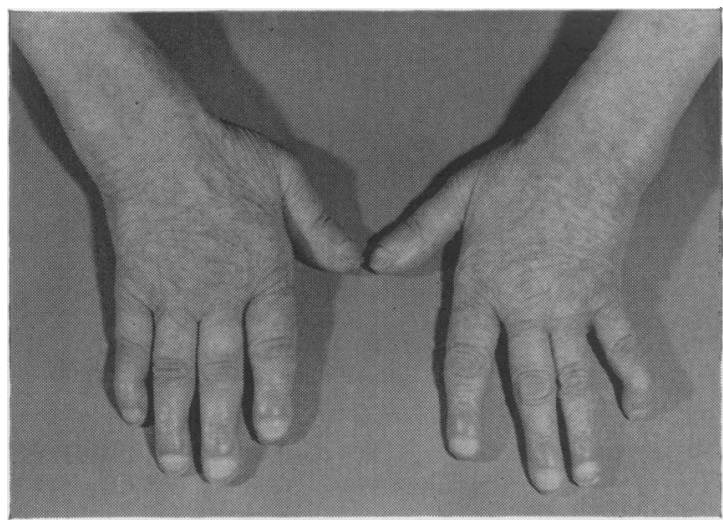

FIG. 2.

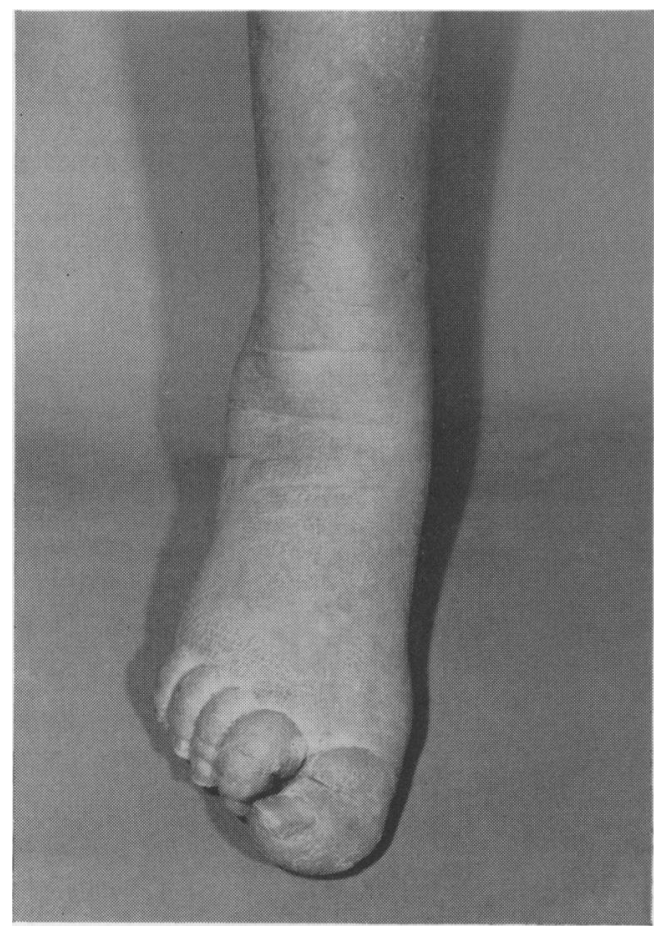

FIG. 3.
There was bilateral exophthalmos and a divergent strabismus. In the left eye, in particular, there was poor elevation, and depression and convergence were limited.

She had moderately severe rheumatoid arthritis in both hands with ulnar deviation and periarticular thickening, together with partial subluxation in the metacarpophalangeal joints. The left knee and wrist joints and both elbow joints were also affected, while large rheumatoid nodules were found on both forearms.

The patient was clinically anaemic, but there was neither splenomegaly nor peripheral neuritis.

Investigations. Haemoglobin $65 \%$. RBC $2 \cdot 7$ million $/ \mathrm{mm}^{3}$ WBC $7000 / \mathrm{mm}^{3}$ with a normal differential count. ESR $120 \mathrm{~mm} / \mathrm{hr}$. Blood film: anisocytosis and poikilocytosis. Diagnex test indicative of achlorhydria. serum vitamin $\mathbf{B}_{12}$ $60 \mu \mu \mathrm{g} / \mathrm{ml}$ (normal 140-900 $\mu \mu \mathrm{g} / \mathrm{ml}$ ). Serum iron $57 \mu \mathrm{g} / 100 \mathrm{ml}$. Iron-binding capacity $199 \mu \mathrm{g} / 100$ ml. Serum proteins $7.4 \mathrm{~g} / 100 \mathrm{ml}$, albumin $2 \cdot 8$, globulin $4.6 \mathrm{~g} / 100 \mathrm{ml}$. Electrophoresis: reduced albumin, raised $\gamma$-globulin. Serum cholesterol $322 \mathrm{mg} / 100 \mathrm{ml}$. Wassermann and Kahn Test negative. Latex test for Rheumatoid Factor negative. Coombs' test negative. FIGLU negative. Serum urea and electrolytes, liver function tests, ECG, chest X-ray normal.

$\mathrm{X}$-rays of the joints showed changes of a rheumatoid type of arthropathy, while the histology of a biopsy specimen was characteristic of a rheumatoid nodule.

Thyroid function studies, performed at a time when all therapy had been withheld for 3 months showed a diminished uptake of ${ }^{131} I$, while administration of thyroid stimulating hormone caused no change in uptake of ${ }^{131} \mathrm{I}$.

Thyroid uptake of ${ }^{131} \mathrm{I}$ at $2 \mathrm{hr}=6 \%$ (normal $10-30 \%$ ) at $24 \mathrm{hr}=8 \%$ (normal $25-55 \%$ ).

These findings were consistent with the diagnosis of primary hypothyroidism.

Antibody tests: She had a trace of thyroid antibodies as shown by a positive fluorescent test for thyroid cytoplasmic antibodies. The tests for gastric parietal cell and intrinsic factor antibodies were also positive, as was the test for the non-organ-specific antinuclear factor. The McKenzie test for the long acting thyroid stimulator (LATS), performed by Dr David El Kabir of Oxford University, showed a moderately high LATS level: $2 \mathrm{hr}$ response $=\mathbf{2 8 8} \pm \mathbf{3 4} \%, 7 \mathrm{hr}$ response $=407 \pm 44 \%, 24 \mathrm{hr}$ response $=346 \pm$ $38 \%$, normal response $=100 \pm 25 \%$.

\section{Discussion}

This case presents several interesting features. 
The occurrence of exophthalmos, pretibial myxoedema and clubbing in association with thyrotoxicosis are well known and thyroid acropachy following thyroidectomy for hyperthyroidism has been described (Sharvill, 1965). However, the presence of exophthalmos in primary myxoedema is said to be extremely infrequent (McKenzie, 1965).

The exophthalmos occurring in thyrotoxicosis was for many years thought to be due to overproduction of thyrotropin (Means, 1944). However, the long acting thyroid stimulator was later described (Adams, 1958) and came to be considered responsible for both exophthalmos and thyrotoxicosis (Pimstone, Hoffenberg \& Black, 1964). Other investigations showed no correlation between LATS assays and exophthalmos (McKenzie, 1961). In a recent group of LATS assays it has been shown that LATS occurred in the majority of cases of a series of patients with exophthalmos and thyrotoxicosis. However, in the same investigation LATS was found in only one of seven cases of exophthalmos occurring without thyrotoxicosis (Pinchera, Pinchera \& Stanbury, 1965).

Our case has a moderately high LATS level, in the presence of exophthalmos and primary myxoedema. This finding has not been previously recorded, possibly because this uncommon association has not been previously investigated in this way.

Another interesting feature of this case is the coexistence of diseases with an autoimmune background. The patient had pernicious anaemia, rheumatoid arthritis and myxoedema, with positive laboratory evidence of autoimmune disorder. This association of conditions with an autoimmune basis has been described frequently (McEachern \& Parnell, 1948; McNicol, 1961) and the occurrence of gastric parietal-cell antibodies in thyroid disorders has been discussed (Doniach, Roitt \& Taylor, 1963). LATS might well by a 7S $\gamma$-globulin (Kriss, Pleshakov \& Chien, (1964) and it has been postulated that it is an autoantibody, produced in response to antigenic stimulation from the thyroid (Adams, 1965). This theory has not yet been substantiated. However, the occurrence of LATS in this case, with its pronounced autoimmune diathesis, fits appropriately into this concept.

\section{Acknowledgments}

My thanks are due to Dr D. Doniach for her helpful comments on this paper and for the antibody investigations undertaken in her department. Due thanks are also given to Dr G. P. Blanshard, Consultant Physician, Hillingdon Hospital, for his advice and for his permission to describe this case, and to Miss Wendy Thomas for her secretarial assistance.

\section{References}

ADAMs, D.D. (1958) The presence of an abnormal thyroid stimulating hormone in the serum of some thyrotoxic patients. J. clin. Endocr. 18, 699.

ADAMS, D.D. (1965) Pathogenesis of the hyperthyroidism of Graves' Disease. Brit. med. J. i, 1015.

DoNIACH, D., RoITT, I.M. \& TAYLOR, K.B. (1963) Autoimmune phenomena in pernicious anaemia. Serological overlap with thyroiditis, thyrotoxicosis and systemic lupus erythematosus. Brit. med. J. i, 1374.

Kriss, J.P., Pleshakov, V. \& Chien, J.R. (1964) Isolation and identification of the long-acting thyroid stimulator and its relation to hyperthyroidism and circumscribed pretibial myxedema. J. clin. Endocr. 24, 1005.

MCEACHERN, D. \& PARNell, J.L. (1948) The relationship of hyperthyroidism to myasthenia gravis. J. clin. Endocr. 8, 842.

MCKENZIE, J.M. (1961) Studies on the thyroid activator of hyperthyroidism. J. clin. Endocr. 21, 635.

MCKENZIE, J.M. (1965) Review: pathogenesis of Graves' Disease: role of the long-acting thyroid stimulator. J. clin. Endocr. 25, 424.

McNicol, G.P. (1961) Thyrotoxicosis associated with pernicious anaemia. Amer. J. med. Sci. 241, 336.

Malknnson, F.D., (1963) Hyperthyroidism, pretibial myxedema and clubbing. Arch. Derm. 88, 303.

MeANS, J.H. (1944) The nature of Graves' Disease with special reference to its ophthalmic components. Amer. $J$. med. Sci. 207, 1.

Plimstone, B.L., Hoffenberg, R. \& Black, E. (1964) Parallel assays of thyrotrophin, long-acting thyroid stimulator and exophthalmos-producing substance in endocrine exophthalmos and pretibial myxedema. J. clin. Endocr. 24, 976.

Pinchera, A., Pinchera, M.G. \& Stanbury, J.B. (1965) Thyrotropin and long-acting thyroid stimulator assays in thyroid disease. J. clin. Endocr. 25, 189.

ShaRvill, D. (1965) Thyroid acropachy, circumscribed myxoedema and exophthalmos. Proc. R. Soc. Med. 58, 424. 